\title{
Analysis of the Process Parameter Influence in Laser Cladding of 316L Stainless Steel
}

\author{
Piera Alvarez ${ }^{1, *}$, M. Ángeles Montealegre ${ }^{2}$, Jose F. Pulido-Jiménez ${ }^{1}$ and \\ Jon Iñaki Arrizubieta 3 (DD \\ 1 Ikergune A.I.E., San Antolin, 3, 20870 Elgoibar, Spain; jose.pj@me.com \\ 2 Talens Systems, Etxe-Tar Group, Polígono Albitxuri, 20, 20870 Elgoibar, Spain; \\ mamontealegre@talenssys.com \\ 3 Department of Mechanical Engineering, University of the Basque Country, Plaza Torres Quevedo 1, \\ 48013 Bilbao, Spain; joninaki.arrizubieta@ehu.eus \\ * Correspondence: palvarez@ikergune.com; Tel.: +34-943-740-600
}

Received: 15 June 2018; Accepted: 13 August 2018; Published: 15 August 2018

\begin{abstract}
Laser Cladding is one of the leading processes within Additive Manufacturing technologies, which has concentrated a considerable amount of effort on its development. In regard to the latter, the current study aims to summarize the influence of the most relevant process parameters in the laser cladding processing of single and compound volumes (solid forms) made from AISI 316L stainless steel powders and using a coaxial nozzle for their deposition. Process speed, applied laser power and powder flow are considered to be the main variables affecting the laser cladding in single clads, whereas overlap percentage and overlapping strategy also become relevant when dealing with multiple clads. By setting appropriate values for each process parameter, the main goal of this paper is to develop a processing window in which a good metallurgical bond between the delivered powder and the substrate is obtained, trying simultaneously to maintain processing times at their lowest value possible. Conventional metallography techniques were performed on the cross sections of the laser tracks to measure the effective dimensions of clads, height and width, as well as the resulting dilution value. Besides the influence of the overlap between contiguous clads and layers, physical defects such as porosity and cracks were also evaluated. Optimum process parameters to maximize productivity were defined as $13 \mathrm{~mm} / \mathrm{s}, 2500 \mathrm{~W}, 30 \%$ of overlap and a $25 \mathrm{~g} / \mathrm{min}$ powder feed rate.
\end{abstract}

Keywords: laser cladding; powder flow; 316L stainless steel

\section{Introduction}

Current development in Additive Manufacturing (AM) has tweaked the product design process itself, by adding the possibility to work on a Computer Assisted Design (CAD) model and create solid metal parts directly from such a model [1]. Within this group, Laser Metal Deposition (LMD) or Laser Cladding (LC) stands as one of the most relevant AM processes in development [2] and, thanks to its versatility as an AM process [3,4], LC technology has become an interesting process for designing and generating parts with complex structures in the industry [5,6]. This novel process allows manufacturing parts or pieces without size restriction or the need of an expensive tooling, and minimizes the material waste by adjusting the required amount of material and laser spot size to the design of the part to be manufactured $[7,8]$. In addition to the latter, when dealing with already manufactured parts, LC is often used to enhance the wear or corrosion resistance of diverse surfaces and as a way of repairing damaged surfaces. Elements such as tools and dies are able to achieve longer life-times thanks to the addition of functional layers on their surface [9], by coating cheaper 
bulk materials with more expensive and mechanically better materials, and thus achieving enhanced surface properties.

Another typical application of LC is the generation of tridimensional geometries on top of a surface [10], similarly to the way inserts or protrusions are placed in a mold. This type of LC process starts with the slicing of a CAD model component and a sequence of equally spaced layers are extracted to be used as an input to the process. Based on this information, deposition strategies are generated in order to fill all areas of each layer [11]. These strategies must comply with the specific requirements of each material, such as overlap percentage, energy density and powder flow, in order to accomplish a good metallurgical bond between the deposited layer and the substrate [12].

In this direction, for instance, dilution is a very relevant parameter when looking for an appropriate process window. Quantitatively, dilution can be calculated as the ratio of molten substrate to molten material during a LC process. The importance of dilution control lies in the fact that, as a consequence of an extensive fusion of the substrate material, mechanical and corrosion properties of the deposited layer can heavily degraded due to the mixture with the substrate [13]. In comparison with a higher energetic process such as arc welding, dilution of the melted substrate in LC is lower, but it is, nonetheless, difficult to find the optimum process parameters to guarantee a proper metallurgical bond [13]. Another disadvantage is that LC is considered a slow process when compared with other additive processes like arc welding [14].

However, besides dilution, physical defects such as porosity and cracking must be evaluated, because their appearance can lead to significant decrease in the mechanical properties of the cladded material and therefore as a whole. These appear mostly when individual clads are overlapped one onto another horizontally or vertically. Main parameters such as speed of the process, applied power and powder flow can affect in different forms the way the geometry of a cladded volume is formed and the resulting geometry and, therefore, defects may appear within the deposited material.

With this in mind, a valid focus to take is to study the LC process in a two-step iterative process: in the beginning, the main process parameters mentioned earlier must be evaluated in order to obtain those with which quality clads with appropriate dilution [15]. Afterwards, and based on these parameters, the overlapping of single clads is studied. For this purpose, transient changes of the parameters must be considered (power decrease in time, overlapping percentage between clads, etc.) in order to minimize the probability of obtaining defects. Following this approach, the main goal of the current work is to present an introductory study of laser cladding, with the aim of achieving a high production manufacturing process window. In order to achieve this goal, the influence of each parameter on the LC process is studied in individual and overlapped clads, as well as the followed strategy when manufacturing solid pieces.

In order to perform the experimental tests, a coaxial nozzle was used for powder deposition and a fiber $6 \mathrm{~kW}$ IPG YLS-6000 is used as the laser power source with a $5 \mathrm{~mm}$ diameter spot. With the configuration of this nozzle it is possible to deliver the powder flux coaxially with the laser beam, thus applying almost equally distributed amounts of powder radially. The latter makes it possible to deposit material in all directions and, therefore, it makes easier to control the accumulated temperature on the workpiece, so that the coaxial laser cladding process may be considered to be independent of the laser track direction [16]. As for the materials used, carbon steel S355 served as substrate for making clads composed of AISI 316L deposited and molten powders.

The first set of experiments were single deposited clads, and the optimization was performed by setting the different values of the main LC process parameters (power, process speed and powder flow) to analyze the influence of each one. The second set of tests consisted of the fabrication of solid, tridimensional figures which were deposited over a plane substrate. The measured effective dimensions of single laser clads from the first set were used to calculate the overlap distance between contiguous clads. To be able to grow layer by layer to form the figures, temperature was not increased too much by regulating laser power for each subsequent layer. Moreover, the strategy of the overlap distribution was studied by proposing three approaches: Contour, Zig Zag and Parallel strategies. 
Each one of them is analyzed since they perform well in controlling the accumulated heat during the process $[9,17]$ and are also appropriate to achieve enough dilution between the delivered powder and the substrate material.

Summarizing, this work is focused on achieving a robust LC manufacturing process parameters window for tridimensional pieces, reducing processing time and ensuring good quality. This study will allow the development of a work methodology in order to gather information about the LC process in a progressively staggered way. As a result, physical characteristics inherent to each one of the stages of the process will be carefully selected and studied, resulting in a cleaner procedure to optimize the process.

\section{Materials and Methods}

\subsection{Material Preparation}

AISI 316L (EN 1.4404) powder, with a particle size range between 44 and $106 \mu \mathrm{m}$, was used as additive material. Its chemical composition is listed in Table 1.

Table 1. Chemical composition (wt \%) of 316L stainless steel [1].

\begin{tabular}{cccccccccc}
\hline & $\mathbf{C}$ & $\mathbf{C r}$ & $\mathbf{N i}$ & $\mathbf{M n}$ & $\mathbf{P}$ & $\mathbf{M o}$ & $\mathbf{S i}$ & $\mathbf{O}$ & $\mathbf{F e}$ \\
\hline wt $\%$ & $\leq 0.03$ & 17.5 & 11.5 & $\leq 2$ & 0.02 & 2.3 & 0.4 & 0.05 & balance \\
\hline
\end{tabular}

A common carbon steel (S355) with a thickness of $8 \mathrm{~mm}$ was used as a substrate in all tests, both to study the influence of the process parameters in single laser cladding tracks and to manufacture thick coatings with the overlap of single cladding tracks.

\subsection{Used Equipment}

The experimental equipment used consisted of a high-power fiber laser, (IPG YLS-6000) releasing radiation at a wavelength of $1070 \mathrm{~nm}$, guided to the optical head by means of a $1000 \mu \mathrm{m}$ core diameter optical fiber. The optical head was mounted in a 3 linear axis system. This optical set up included a $120 \mathrm{~mm}$ collimating lens and a $550 \mathrm{~mm}$ focusing lens that generated a $5 \mathrm{~mm}$ diameter spot.

A coaxial nozzle was used for experimental tests. Nitrogen was used as a carrier gas to deliver the powder from the powder feeder to the melt pool and the same gas was used to generate a protective atmosphere during the deposition process. Metallic powder particles were placed in a GTV powder feeder (from GTV Verschleißschutz GmbH Company, Luckenbach, Germany) and delivered to the process zone through a coaxial nozzle. A schematic layout of the used laser cladding system is shown in Figure 1.

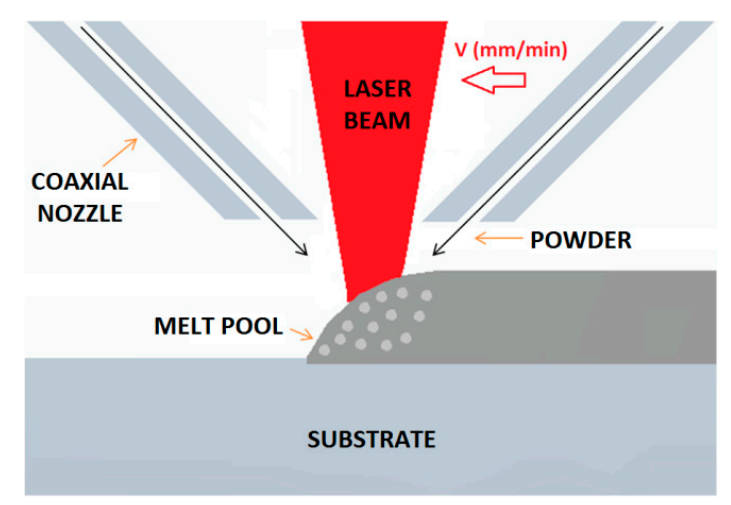

Figure 1. Schematic layout of the coaxial laser cladding system. 


\subsection{Experimental Procedure}

First, the main parameters involved in the deposition of single clads were studied. The range of levels of the main process parameters studied in this paper were between 2000 and $4000 \mathrm{~W}$ for the laser power, $13-27 \mathrm{~mm} / \mathrm{s}$ for the process speed and $12-31 \mathrm{~g} / \mathrm{min}$ for the powder flow rate. Other process parameters were kept constant and are shown in Table 2.

Table 2. Common process parameters.

\begin{tabular}{ccc}
\hline Laser Focus Distance (mm) & Carrier Gas (L/min) & Shielding Gas (L/min) \\
\hline 550 & 3 & 5 \\
\hline
\end{tabular}

Second, multiple clad were deposited by following different strategies and increasing the coating thickness layer by layer. The purpose of building solid forms after generating single clads was to develop a stable coating process for bigger areas, seeking to minimize defects, such as lack of fusion, and to maintain good mechanical properties of the deposited material.

The value range of the main parameters was derived from the first part and the effective dimensions measured in single clad experiments were considered for the calculation of the overlapping percentage (between $20 \%$ and $40 \%$ ). In particular, the width of the clad was used to calculate the percentage of overlap between contiguous clads, and the height was used to calculate the mean increase per each new layer (with multilayered volumes). For the latter, the height of a layer was measured with a gauge and the distance between the nozzle and the workpiece was updated for each subsequent layer. The dimension range of the solid forms created was between $20 \times 20 \mathrm{~mm}^{2}$ and $30 \times 30 \mathrm{~mm}^{2}$, and their heights depended on the number of layers deposited.

Besides the overlapping percentage, the strategy used for generating layers was also considered as a process parameter for solid forms. Figure 2 shows the sketches of the three types of strategies applied to deposit the powder flow. The first strategy consists on creating a contour of the form, by growing a wall with square form in the first place. The second draws Zig Zag tracks as the coaxial nozzle moves back and forth parallel to the same direction all the time [17]. Finally, the third one is called Parallel (also known as Raster strategy [14]): the laser clads are deposited in parallel, starting and finishing at the same point.

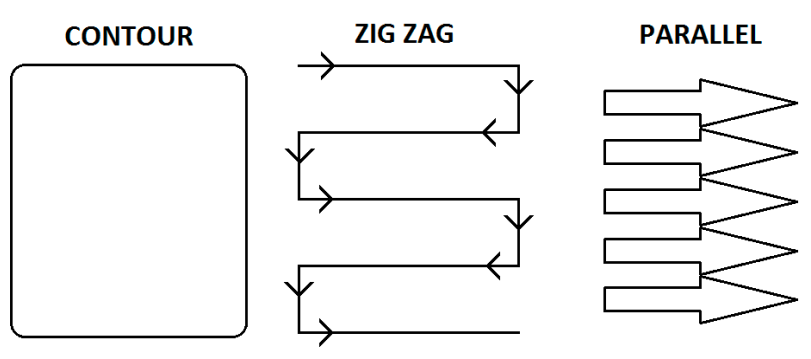

Figure 2. Sketches of type of strategies applied.

Conventional metallography techniques were performed on the cross sections of the LC deposited tracks, to measure the effective dimensions of clads. The preparation of the cross sections of clads began with grinding foils, and then a polishing stage was applied with a cloth and diamond particles with a size of $3 \mu \mathrm{m}$ to remove the fine scratches. After that, they were etched with the commercial V2A etching, which is a special reactive to reveal stainless steel microstructure. Micrographs of cross sections were analyzed using an optical microscope (Optika). 


\section{Results and Discussion}

\subsection{Individual Clad Experiments}

Figure 3 shows a resume of the average of the geometrical values (height and width) achieved for the studied different laser processes parameters (each test was repeated twice) and the three values of powder flow. Results of the metallographic analysis performed in the cladded specimens are represented in the following paragraphs. These results will be primarily evaluated according to their dilution values, which should be in the range of $10-20 \%[18,19]$. The dilution has been calculated according to the Equation (1). In Figure 4 a scheme of the nomenclature used to define the dimensions of the clads is shown.

$$
\text { Dilution }[\%]=\frac{\text { Dilution }}{\text { Height }+ \text { Dilution }} \cdot 100
$$

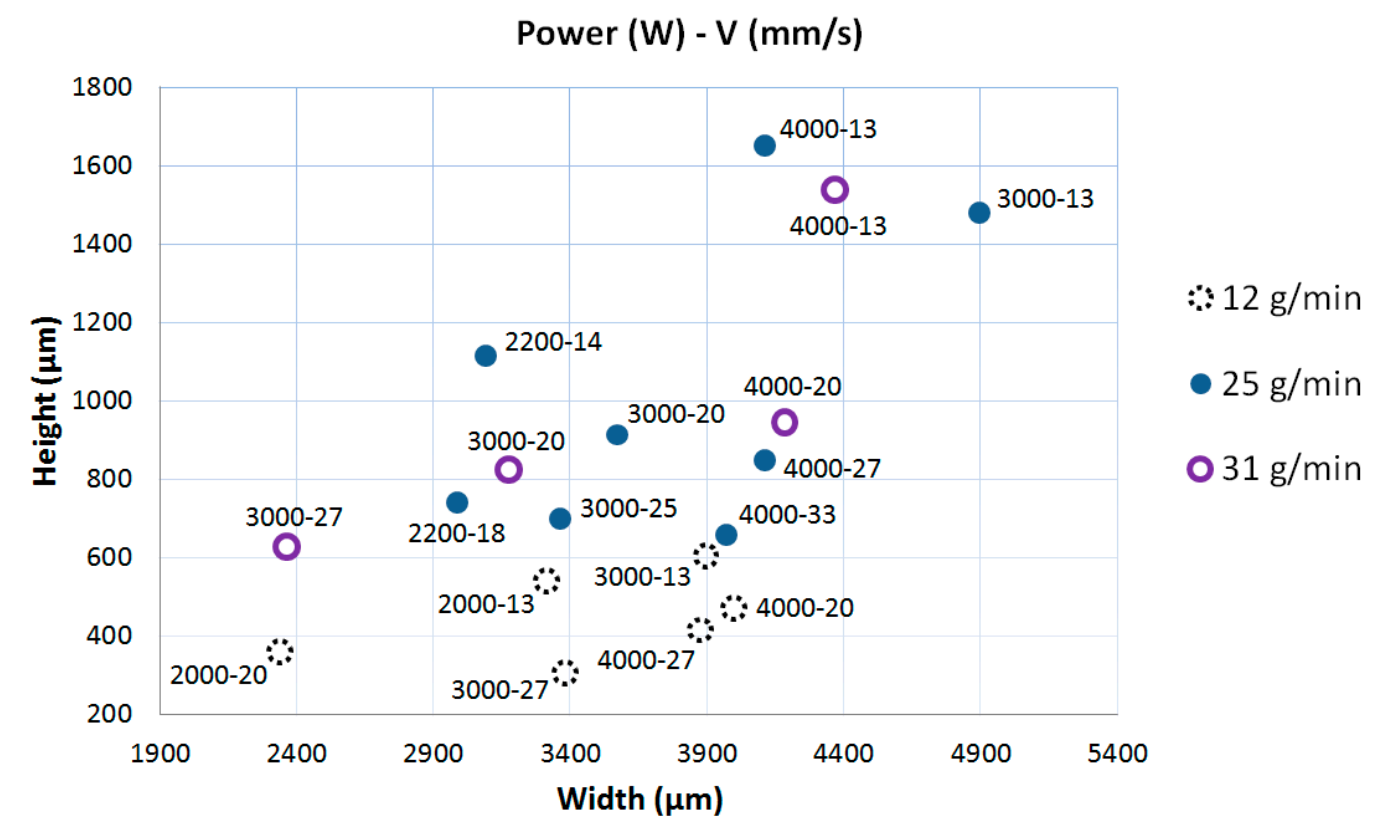

Figure 3. Dimensions of clads (height vs width) with their process parameters inside the graphic (Power $(\mathrm{W})-\mathrm{V}(\mathrm{mm} / \mathrm{s}))$.

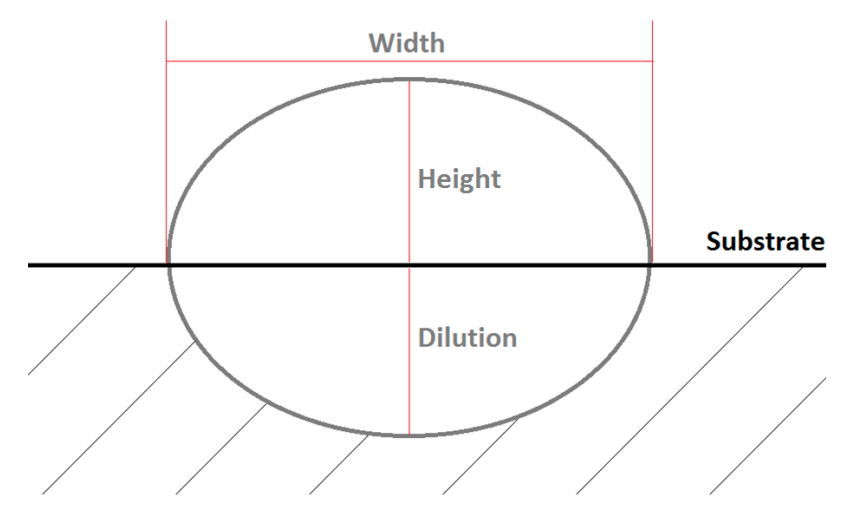

Figure 4. Sketch of the measured dimensions of clads.

Beginning with the case of $12 \mathrm{~g} / \mathrm{min}$ of powder flow, it can be concluded from the results shown in Table 3 that the mean height of clads was slightly lower than $600 \mu \mathrm{m}$. The obtained dilution values range from $20 \%$ to more than $35 \%$, as observed in the cases of $20-27 \mathrm{~mm} / \mathrm{s}$ and $3000-4000 \mathrm{~W}$. The high 
dilution values when compared to the objective values (10-20\%) can be understood from the fact that there might not be enough amount of powder for the combination of spot size $(\varnothing=5 \mathrm{~mm})$ and the laser power values used. When this happens, a portion of the energy—which is higher than desired-affects the substrate directly because there is not enough powder to absorb it. The energy absorption in the substrate leads to a net heat increase, causing the surface to melt and therefore increase its absorption coefficient [20]. In the end, if too high energy densities are used for the employed powder flow rate, a re-melting of the substrate is obtained, which causes an inappropriate relationship between powder flow and laser power, making the heat-affected zone of the substrate bigger than the clad width [21].

Table 3. Experiments with powder flow of $12 \mathrm{~g} / \mathrm{min}$.

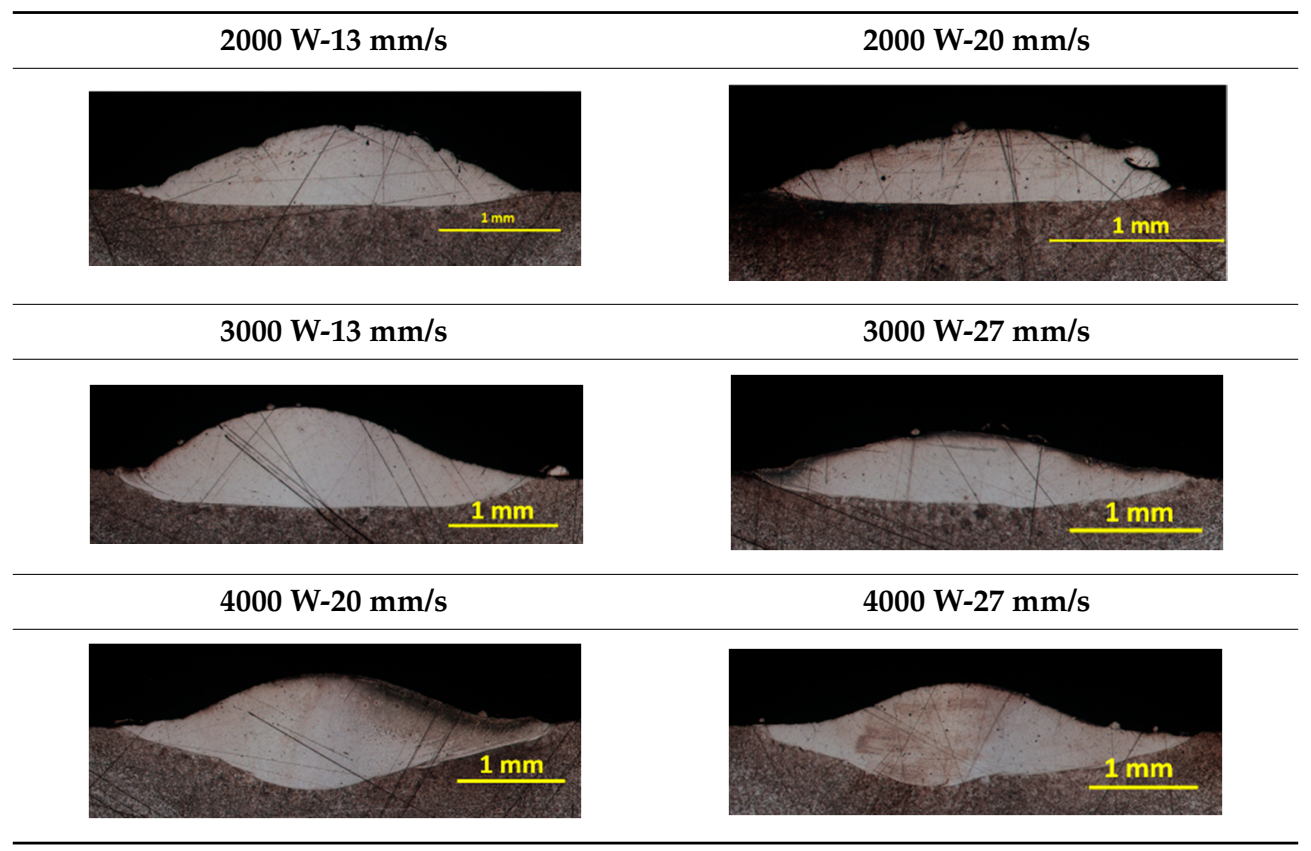

When comparing the obtained results for equal laser power and powder flow values (Figure 3), the height of the clads is higher for the minimum value of process speed $(13 \mathrm{~mm} / \mathrm{s})$ than those made with the maximum value $(27 \mathrm{~mm} / \mathrm{s})$. Therefore, going slower helped to deposit a higher amount of energy to the LC process [18,19]. This is observed in the couples of tests for $2000 \mathrm{~W}, 3000 \mathrm{~W}$ and $4000 \mathrm{~W}$ shown in Table 3.

The second value of powder flow to analyze is $25 \mathrm{~g} / \mathrm{min}$. On the one side, for the tests with the lowest laser power values shown in Table 4, the mean percentage of dilution was less than $20 \%$ and the mean clad dimensions measured in this tests selection are composed by a height of more than $1 \mathrm{~mm}$ and a width of more than $3 \mathrm{~mm}$. On the other side, the different power values combined with the highest process speed seem to be too fast for the power value used, achieving clads with less than $1 \mathrm{~mm}$ in height. Therefore, the interaction time found at higher process speeds did not allow the powder enough time to be completely molten $[18,19]$. From this group, the test with the highest values of laser power $(4000 \mathrm{~W})$ and process speed $(27 \mathrm{~mm} / \mathrm{s})$ shows a dilution ratio higher than $20 \%$ (not desirable).

It is important to highlight that the cross section of the test with $2000 \mathrm{~W}$ and $20 \mathrm{~mm} / \mathrm{s}$ parameters is not shown because there was not metallurgical bonding between laser track and the substrate, so a spallation of the clad occurred. In this case, laser power value used was the lowest studied in this work and process speed was set at its highest value, meaning that energy density reached was not enough to guarantee a metallurgical bonding between the clad and the substrate [20]. 
Table 4. Experiments with powder flow of $25 \mathrm{~g} / \mathrm{min}$.

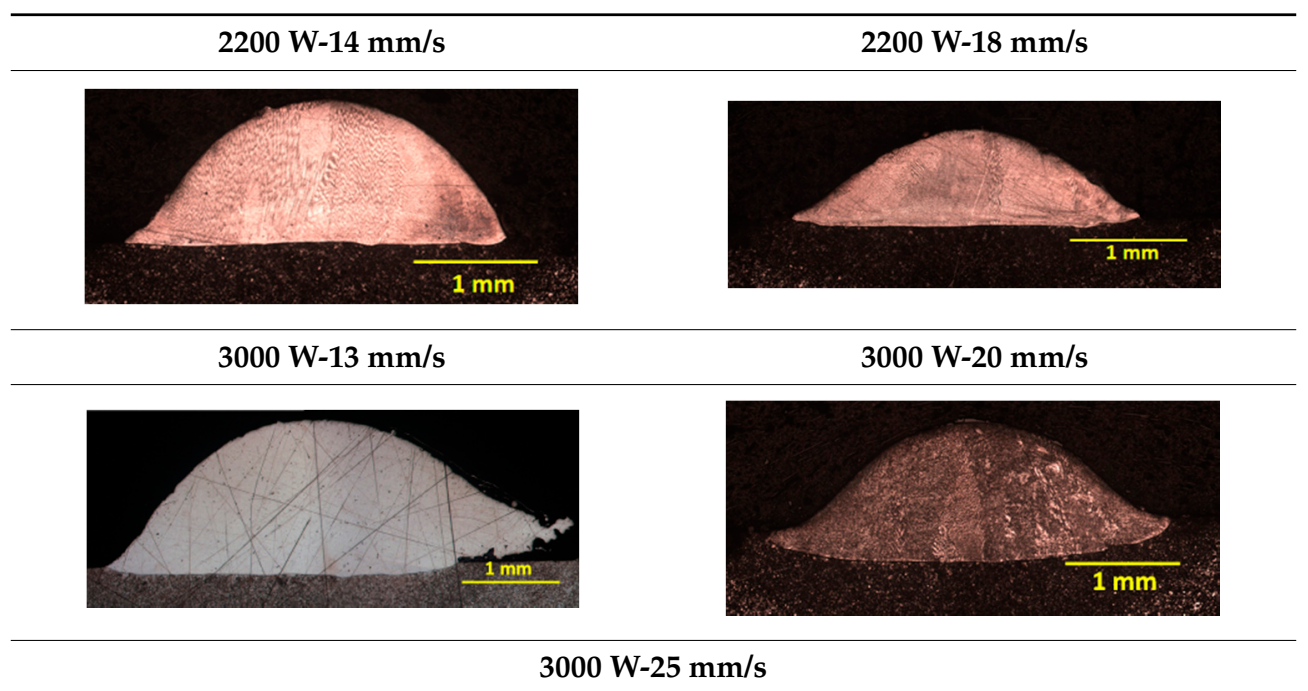
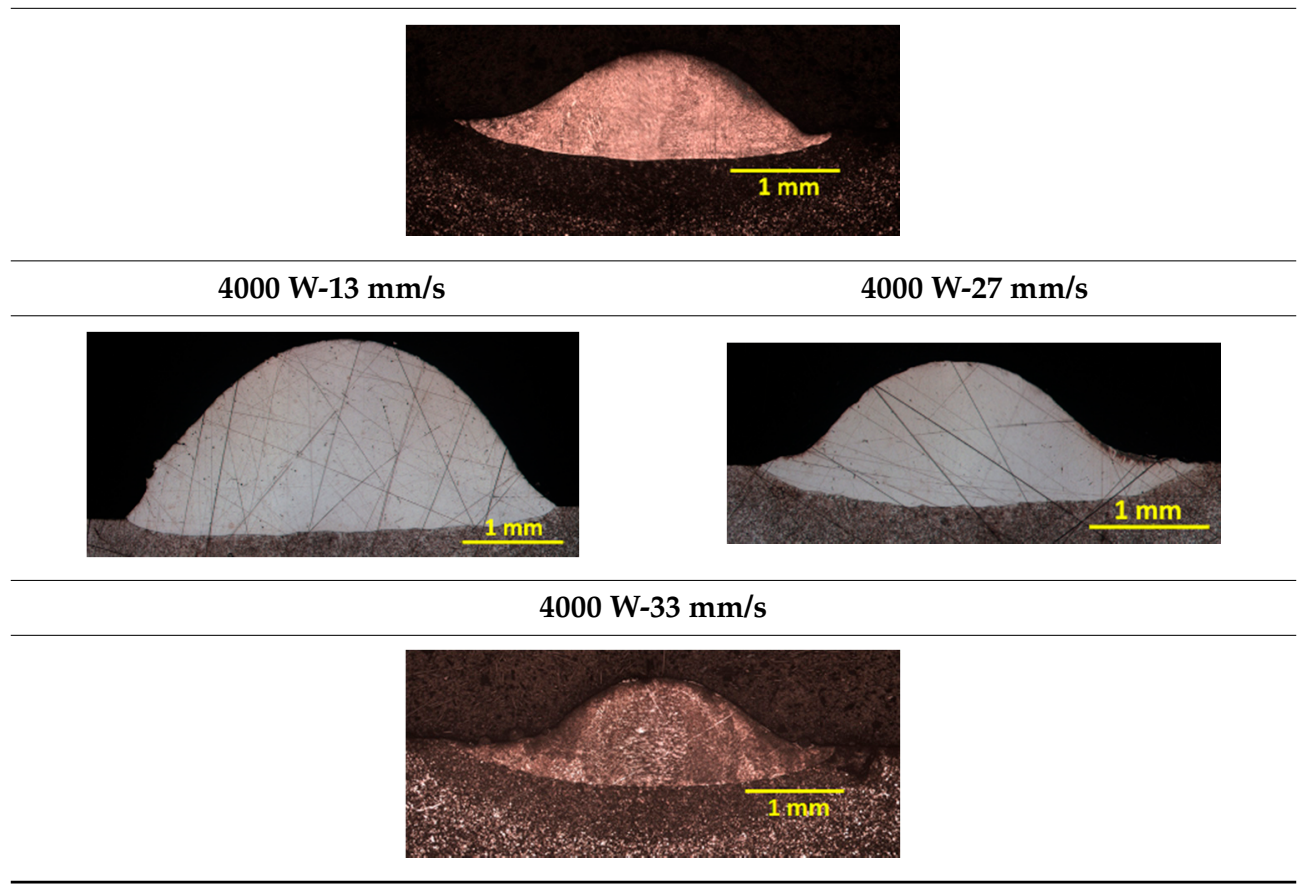

The last value of powder flow analyzed was $31 \mathrm{~g} / \mathrm{min}$ and metallographic results are shown in Table 5. It can be observed that only the highest laser power setting $(4000 \mathrm{~W})$ and minimum process speed $(13 \mathrm{~mm} / \mathrm{s})$ combination, which are also represented in the Figure 3, was able to achieve more than $1 \mathrm{~mm}$ in height and more than $4 \mathrm{~mm}$ in width, although the dilution percentage was $30 \%$.

Lower widths and heights found in the rest of the tests can be explained from the process speed values chosen for the design of experiments, as they were apparently too high and therefore cooling time was left to be too short, meaning that was not possible to melt all the delivered powder $[18,19]$. Conclusions can be drawn also from the measured dilution percentages at different laser power value settings: when using $3000 \mathrm{~W}$, dilution reached $20 \%$ and with $4000 \mathrm{~W}$ the dilution went up to more than $35 \%$.

No results are shown for the test with $2000 \mathrm{~W}$ and $13 \mathrm{~mm} / \mathrm{s}$ process parameters, due to the lack of metallurgical bonding between laser track and the substrate. In this case, the energy density was too low to melt the total amount of delivered powder, causing the powder grains to absorb most of the 
energy. Therefore, the substrate did not melt and dilution did not take place, leaving an inadequately bonded clad upon the surface of the substrate [20].

Table 5. Experiments with powder flow of $31 \mathrm{~g} / \mathrm{min}$.

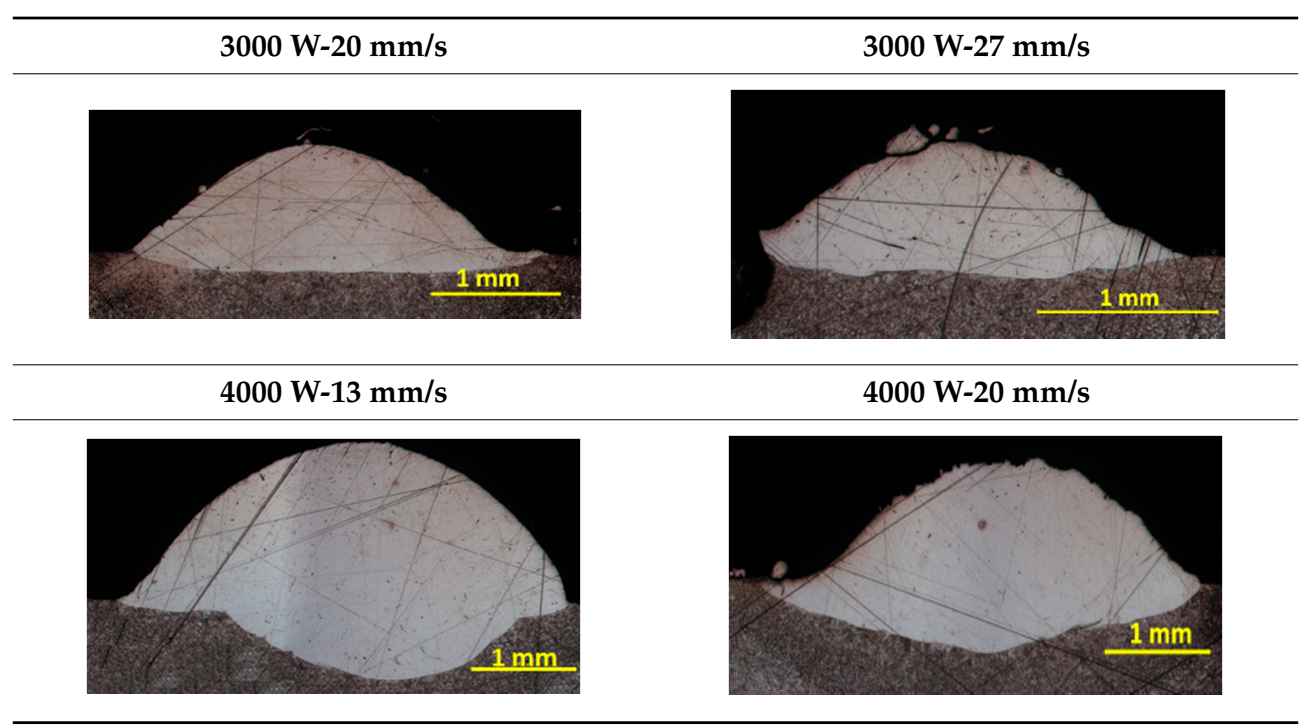

\subsection{Multiple Clad Experiments (Solid Forms)}

From the single clad experiments, it is clear that the intermediate setting of powder flow $(25 \mathrm{~g} / \mathrm{min})$ groups provided the best results when seeking to optimize dilution ratios (between 5 and 20\%). Within this group, on the other hand, tests with maximum height for the power levels studied (range of 2000-4000 W) were found to be those with the lowest processing speeds ( $13 \mathrm{~mm} / \mathrm{s}$ ). Those parameters were used as reference process parameters for the fabrication of solid forms. Nonetheless, in preliminary tests it was found that the highest power level $(4000 \mathrm{~W})$ was difficult to control when depositing multiple clads side by side, taking into account that power regulation was done only after a layer was finished. With this in mind, process speed value was set to be $13 \mathrm{~mm} / \mathrm{s}$ and laser power value was switched between $2000 \mathrm{~W}$ and $3000 \mathrm{~W}$ for the fabrication of multiple clad volumes.

The first of the strategies to be performed was the Contour. The general aspect of the contour samples are shown in Figure 5, where it can be observed that the cladding showed good aspect in geometry. Analyzing the cross section of the wall in Figure 6, it is important to notice that the deposited material was porosity and cracking free and good metallurgical bonding was obtained between the substrate and the clad, as can be observed with more detail in Figure $6 \mathrm{~b}$.
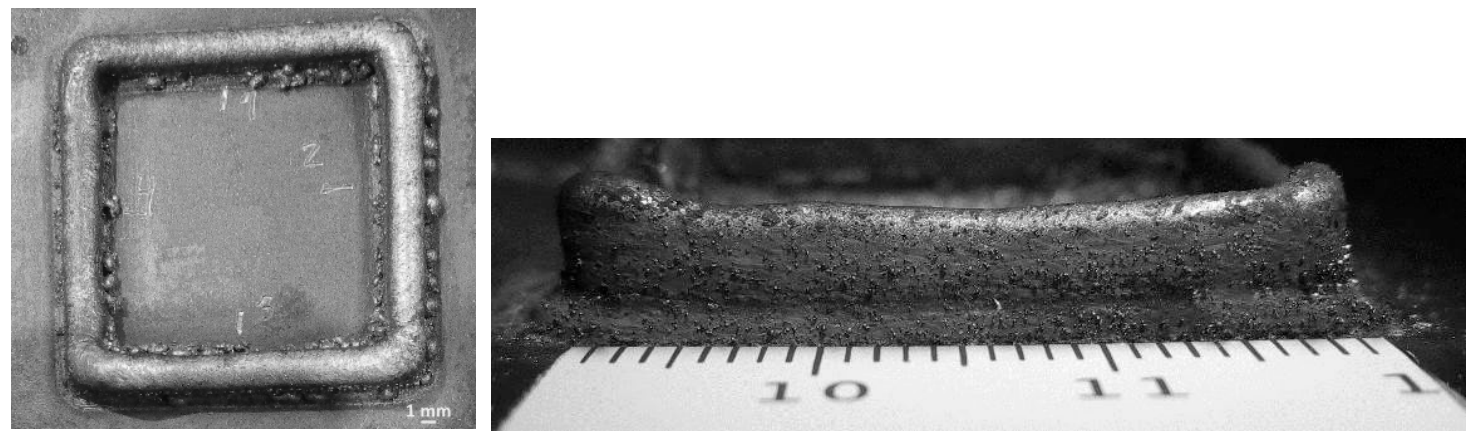

Figure 5. Picture of the contour, general view and a detail of the wall. 

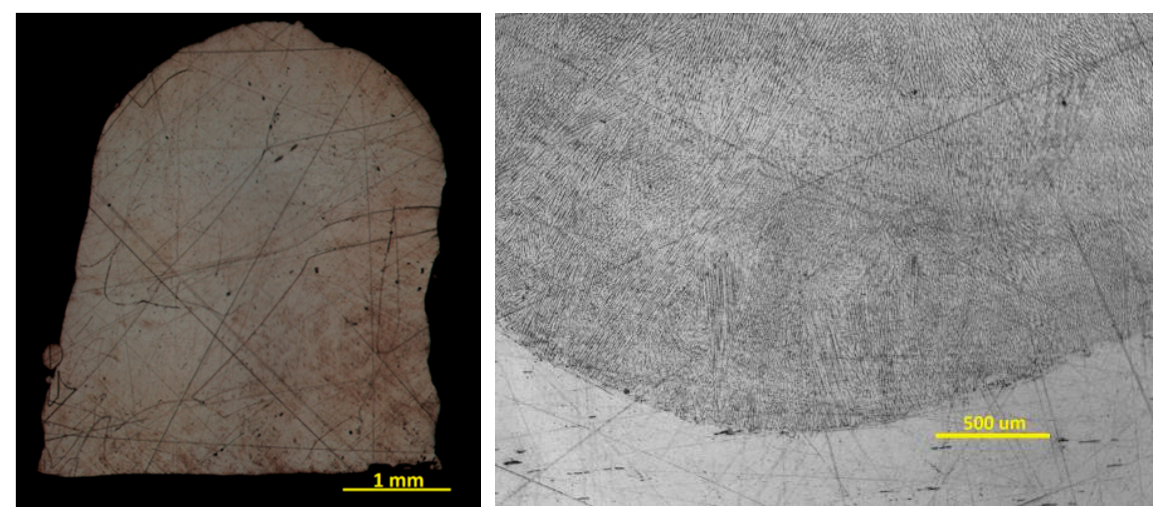

Figure 6. Micrograph of cross sections of a wall and a detail of bonding zone.

It is worth mentioning that, due to the setup employed to manufacture this piece, it was difficult to maintain a homogeneous height in the whole contour, especially near the turning radius, because of the deceleration of the machine axes before reaching these points. This can be observed in Figure 5, where there is a slight variation in height in the middle of the wall $(4 \mathrm{~mm})$ compared with the corner $(4.8 \mathrm{~mm})$.

Following with the experiments of solid forms, the next strategies applied were the Zig Zag and Parallel strategies. Unlike the single clads, for the study of solid forms is necessary to add the percentage of the overlap between contiguous clads as an influence parameter. Furthermore, it is necessary to study the relationship between the percentage of the overlap and the amount of powder flow to be melted [11]. It is important to seek for an optimal combination of both parameters to guarantee that there is not lack of fusion in the manufactured part, as well as to reduce processing time $[14,17]$. As indicated earlier, the range of overlap percentage studied in this work was within 20 and $40 \%$.

Figures 7 and 8 show two tests that were manufactured following the Zig Zag strategy. The first one was made with a $40 \%$ overlap (one layer), while in the second the overlap value was set to $30 \%$ (two layers). The main difference that can be seen from both tests is the homogeneity of the resulting surface. In Test 1 it is observed that the delivered powder was piled up, obtaining a rough surface due to the high percentage of overlap, which was the reason for not continuing with the test and depositing a second layer, since it would achieve poor adhesion between layers. Instead, in Test 2 the edges were not very sharp, but the surface was more homogenous than in the former case, because of the lower percentage of overlap used, so that a second layer was grown to verify if good adhesion between the layers would be achieved. Common aspects can be observed in both tests: they are free of porosity and cracking and there is good adhesion between the substrate and the deposited powder.

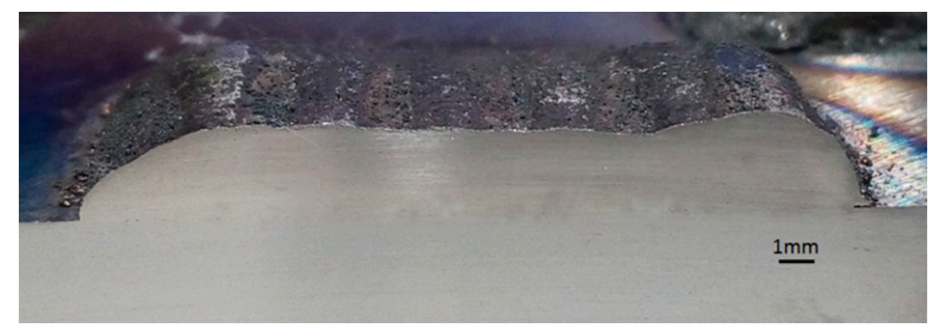

Figure 7. Macrograph of a cross section following the Zig Zag strategy. 


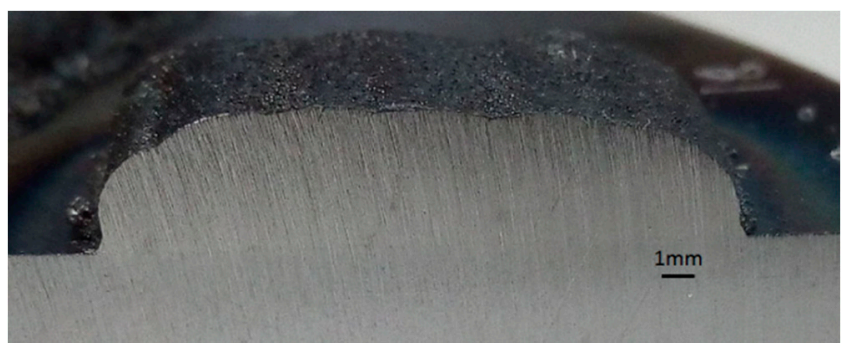

Figure 8. Macrograph of a cross section following the Zig Zag strategy.

Finally, the volumes made with the Parallel strategy can be observed in Figures 9 and 10. Only one layer was deposited in the case of Figure 9, allowing the study of the overlap between contiguous cladding tracks. The result showed good adhesion between the substrate and deposited powder and no porosity or cracks appear.

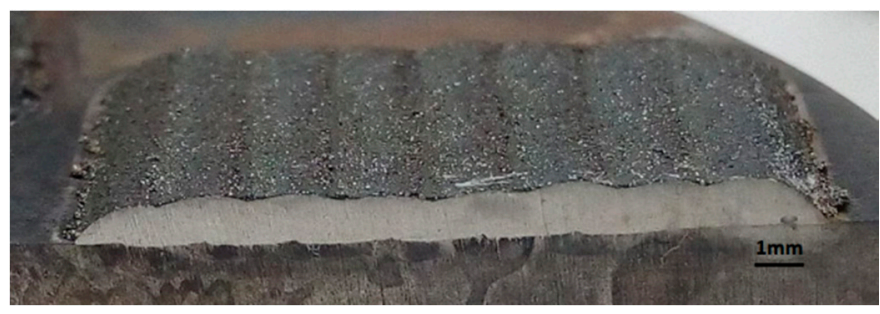

Figure 9. Macrograph of a cross section following the Parallel strategy.

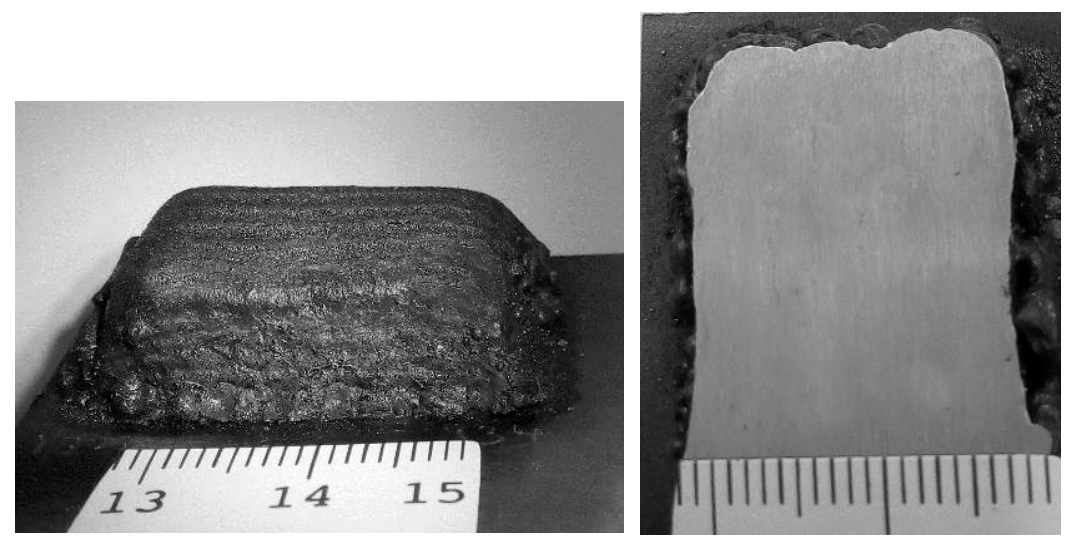

Figure 10. Pictures of general views of a solid piece and its machined surface.

\subsection{Parameter Reduction and Building of a Solid Form}

In order to test one of the strategies used in the previous section, a multiple clad, multilayered volume was built with the process settings chosen between Parallel and Zig Zag strategies. The Parallel strategy was found to have a more continuous height and, therefore, a more homogeneous surface and was thus used as an input for the solid piece proposed.

The multiple clad volume generated was built layer by layer following a Parallel strategy with a total of 10 layers, and the result obtained is presented in Figure 10. In this case, the surface was machined to analyze if porosity, cracks or lack of material had appeared, and no defects were found. Actually, it should be mentioned that, sometimes, depending on the final application of the manufactured piece, it is necessary to apply a finish machining operation to the additively manufactured pieces due to the surface quality. Furthermore, the combination of both manufacturing techniques is defined as hybrid manufacturing, which is being developed in the industry [22]. 
Total height was measured to be around $8 \mathrm{~mm}$. It is important to notice that, even though a single clad grows more than $1 \mathrm{~mm}$ under the process parameters chosen, continuous, multiple clads will have a different net height because of the overlapping final geometries [23].

Following the steps in this work, process parameters chosen to be suitable for cladding 316L stainless steel in solid forms with the coaxial nozzle used are:

- Power range: 2000-3000 W

- Process speed: $13 \mathrm{~mm} / \mathrm{s}$

- Powder flow: $25 \mathrm{~g} / \mathrm{min}$

- Overlap percentage: $30 \%$

- Increase in average height per layer: $0.8 \mathrm{~mm}$

\section{Conclusions}

This paper seeks to analyze the influence of the main laser process parameters (laser power, process speed and powder flow rate) in the geometry of a single laser clad, in order to achieve the optimal process parameters to build, layer by layer, a solid piece as a first approach. Regarding the powder flow, as can be observed in Figure 3, in order to achieve the better relation between the height and the width of the clads, for a $12 \mathrm{~g} / \mathrm{min}$ powder flow the optimum conditions are $3000 \mathrm{~W}-13 \mathrm{~mm} / \mathrm{s}$ with a height of $600 \mu \mathrm{m}$ and width of $3900 \mu \mathrm{m}$ with height of $1500 \mu \mathrm{m}$ and width of $4900 \mu \mathrm{m}$; whereas for the case of $25 \mathrm{~g} / \mathrm{min}, 3000 \mathrm{~W}$ and $13 \mathrm{~mm} / \mathrm{s}$ are useful; and for $31 \mathrm{~g} / \mathrm{min}$ the conditions are $4000 \mathrm{~W}-13 \mathrm{~mm} / \mathrm{s}$ where the height was $1550 \mu \mathrm{m}$ and width $4450 \mu \mathrm{m}$.

The main conclusions derived from this study are the following:

- A good metallurgical bond was achieved when depositing AISI 316L stainless steel via LC, thanks to the good relation between $25 \mathrm{~g} / \mathrm{min}$ of powder flow and 30\% of overlap, which guaranteed a dilution value of less than $20 \%$ in lower process time and, in the case of solid forms, without lack of fusions. In addition, it is necessary to modulate the laser power during the coating process (from $3000 \mathrm{~W}$ to $2000 \mathrm{~W}$ ), in order to maintain control of the process, avoiding overheating of the piece.

- Regarding the strategies studies, it can be seen that the Zig Zag strategy is the best to ensure the maximum increase of the height of the deposited layer, and the Parallel strategy can be used to achieve a more homogeneous layer height.

Author Contributions: P.A.: conceived, designed and performed the experiments, analyzed the micrographs, discussed the results, and took charge of writing the article. M.Á.M.: Conceived and designed the experiments, discussed the results and supervised the writing. J.F.P.-J.: Performed the experiments and discussed the results. J.I.A.: Assisted in writing the article.

Funding: This research was funded by the Spanish Centre for the Development of Industrial Technology (CDTI) and the European Union through the European Regional Development Fund under Grant Number: IDI-20141335.

Acknowledgments: The authors would like to thank Talens System-Etxe-Tar Group for supporting this study.

Conflicts of Interest: The authors declare no conflicts of interest.

\section{References}

1. Ziętala, M.; Durejko, T.; Polański, M.; Kunce, I.; Płociński, T.; Zieliński, W.; Łazińska, M.; Stępniowski, W.; Czujko, T.; Kurzydłowski, K.J.; et al. The microstructure, mechanical properties and corrosion resistance of 316 L stainless steel fabricated using laser engineered net shaping. Mater. Sci. Eng. A 2016, 677, 1-10. [CrossRef]

2. Pei, Y.T.; De Hosson, J.T.M. Functionally graded materials produced by Laser cladding. Acta Mater. 2000, 48, 2617-2624. [CrossRef]

3. Pinkerton, A.J. Lasers in additive manufacturing. Opt. Laser Technol. 2016, 78, 25-32. [CrossRef] 
4. Castro, G.; Rodriguez, J.; Montealegre, M.A.; Arias, J.L.; Yañez, A.; Panedas, S.; Rey, L. Laser additive manufacturing of high added value pieces. Procedia Eng. 2015, 132, 102-109. [CrossRef]

5. MANUFUTURE Platform. Strategic Research Agenda: Assuring the Future of a Competitive and Sustainable Manufacturing in Europe. 2006. Available online: http:/ / www.manufuture.org/strategic-research-agenda/ (accessed on 14 August 2018).

6. Cortina, M.; Arrizubieta, J.I.; Calleja, A.; Ukar, E.; Alberdi, A. Case Study to Illustrate the Potential of Conformal Cooling Channels for Hot Stamping Dies Manufactured Using Hybrid Process of Laser Metal Deposition (LMD) and Milling. Preprints 2017, 2017120076. [CrossRef]

7. Langefeld, B. Additive Manufacturing. A Game Changer for the Manufacturing Industry? Roland Berger Strategy Consultants: Munich, Germany, 2013.

8. Montealegre, M.A.; Vidal, F.; Mann, S.; Abels, P.; Motmans, F.; Walter, A.; Kogel-Hollacher, M.; Palatka, P.; Franch, R.; Lovec, F. Adaptive laser cladding system with variable spot sizes. In Proceedings of the 2013 International Congress on Applications of Lasers and Electro-Optics, Congress Proceedings (ICALEO), Miami, FL, USA, 6-10 October 2013; pp. 950-954, ISBN 978-0-912035-98-7.

9. Klocke, F.; Brecher, C.; Heinen, D.; Rosen, C.; Breitbach, T. Flexible scanner-based laser surface treatment. Phys. Procedia 2010, 5, 467-475. [CrossRef]

10. Pekkarinen, J. Laser Cladding with Scanning Optics. Ph.D. Thesis, University of Technology, Lappeenranta, Finland, 2014.

11. Li, Y.; Yang, H.; Lin, X.; Huang, W.; Li, J.; Zhou, Y. The influences of processing parameters on forming characterizations during laser rapid forming. Mater. Sci. Eng. A 2003, 360, 18-25. [CrossRef]

12. Calleja, A.; Tabernero, I.; Fernández, A.; Celaya, A.; Lamikiz, A. Improvement of strategies and parameters for multi-axis laser cladding operations. Opt. Lasers Eng. 2014, 56, 113-120. [CrossRef]

13. Goodarzi, D.M.; Pekkarinen, J.; Salminen, A. Effect of process parameters in laser cladding on substrate melted areas and the substrate melted shape. J. Laser Appl. 2015, 27, S29201. [CrossRef]

14. Ding, D. Process Planning for Robotic Wire ARC Additive Manufacturing. Ph.D. Thesis, University of Wollongong, Wollongong, Australia, 2015.

15. Wang, Z.; Palmer, T.A.; Beese, A.M. Effect of processing parameters on microstructure and tensile properties of austenitic stainless steel $304 \mathrm{~L}$ made by directed energy deposition additive manufacturing. Acta Mater. 2016, 110, 226-235. [CrossRef]

16. De Oliveira, U.; Ocelik, V.; De Hosson, J.T.M. Analysis of coaxial laser cladding processing conditions. Surf. Coat. Technol. 2005, 197, 127-136. [CrossRef]

17. Routhu, S. 2-D path Planning for Direct Laser Deposition Process. Master's Thesis, Missouri University of Science and Technology, Rolla, MO, USA, 2010.

18. Huang, Y. Characterization of dilution action in laser-induction hybrid cladding. Opt. Laser Technol. 2011, 43, 965-973. [CrossRef]

19. Song, B.; Hussain, T.; Voisey, K.T. Laser cladding of Ni50Cr: A parametric and dilution study. Phys. Procedia 2016, 83, 706-715. [CrossRef]

20. Wolf, M. Improving the Efficiency of the DMLD Process, How Particle Size and Laser Spot Size Influence process Quality and Efficiency. Laser Tech. J. 2016, 13, 32-34. [CrossRef]

21. Ocylok, S.; Alexeev, E.; Mann, S.; Weisheit, A.; Wissenbach, K.; Kelbassa, I. Correlations of melt pool geometry and process parameters during laser metal deposition by coaxial process monitoring. Phys. Procedia 2014, 56, 228-238. [CrossRef]

22. Kaynak, Y.; Kitay, O. Porosity, surface quality, microhardness and microstructure of selective laser melted 316 L stainless steel resulting from finish machning. J. Manuf. Mater. Process. 2018, 2, 36.

23. Nenadl, O.; Ocelík, V.; Palavra, A.; De Hosson, J.T.M. The prediction of coating geometry from main processing parameters in laser cladding. Phys. Procedia 2014, 56, 220-227. [CrossRef]

(C) 2018 by the authors. Licensee MDPI, Basel, Switzerland. This article is an open access article distributed under the terms and conditions of the Creative Commons Attribution (CC BY) license (http:/ / creativecommons.org/licenses/by/4.0/). 